\title{
Serebral palsi tedavisinde baklofen pompası uygulamasında güncel durum
}

\author{
Latest advances at baclofen pump in cerebral palsy treatment
}

\author{
Elif Bolat
}

Ege Üniversitesi Tıp Fakültesi Hastanesi, Beyin ve Sinir Cerrahisi Kliniği, Bornova, İzmir

\begin{abstract}
Serebral palsi, gelişmekte olan fetal ya da infant beyninde ortaya çıkan, progresif (ilerleyici) olmayan bozukluklar sonucu görülen, hareket ve duruşun bir grup gelişimsel bozukluğudur. Motor kayıpların yanında sıklıkla epilepsi, sekonder kas-iskelet sistemi problemleri, duyu ve algı bozuklukları, bilişsel bozukluklar ve davranışsal problemler görülebilir. Etkilenen hastalarda görülen ciddi motor fonksiyon bozukluğu ve ağrı nedeniyle yürüme, beslenme, giyinme, tuvalet ihtiyacını giderme gibi günlük aktiviteleri gerçekleştirme ve bağımsız hareket edebilme güçleşir. Serebral palside görülen spastisite veya distoninin tedavisinde standart bir fikir birliği yoktur. Spastisite derecesi ve neden olduğu klinik etkiler multidisipliner olarak ayrıntılı olarak değerlendirildikten sonra uygun bir tedavi planı oluşturulmalıdır. Spastisite tedavisinde; oral antispastik ajanlar gibi farmakolojik tedaviler, fizik tedavi, lokal botulinum toksin enjeksiyonları ilk basamak tedaviler olarak kabul edilmekle birlikte etkinlikleri her zaman istenilen düzeyde değildir. Bu nedenle zaman zaman ortopedik ve intratekal baklofen tedavisi gibi nöroşirürjikal prosedürlere ihtiyaç duyulabilmektedir.
\end{abstract}

Anahtar sözcükler: serebral palsi; baklofen; intratekal tedavi
Cerebral palsy is a group of developmental disorder of movement and posture that occurs in developing fetal or infant brain because of non-progressive pathologies. Epilepsy, secondary musculoskeletal system problems, cognitive disorders and behavioral problems can be generally seen beside motor functional deficiencies. Performing daily activities like gait, feeding, clothing and toileting are affected because of severe motor disability and pain in cerebral palsy patients. There is not a consensus in the treatment of spasticity and distony seen in cerebral palsy. An appropriate treatment strategy must be decided after evaluating the degree of spasticity and clinical features in a multidisciplinary manner. Pharmacologic treatments as oral antispastic agents, physical therapy, local Botulinum toxin injections are the first line treatment modalities in spasticity therapy but they are not always effective. So orthopedic or neurosurgical procedures like intratechal baclofen therapy can be also needed in the treatment of spasticity.

Key words: cerebral palsy; baclofen; intrathecal therapy erebral palsi, gelişmekte olan fetal beyinde ya da infant (süt çocuğu) beyninde ortaya çıkan, progresif (ilerleyici) olmayan bozukluklar sonucu görülen, hareket ve duruşun bir grup gelişimsel bozukluğudur. Motor kayıpların yanında sıklıkla epilepsi, sekonder kas-iskelet sistemi problemleri, duyu ve algı bozuklukları, bilişsel bozukluklar ve davranışsal problemler görülebilir. ${ }^{[1-3]}$ Etkilenen hastalarda görülen ciddi motor fonksiyon bozukluğu ve ağrı nedeniyle yürüme, beslenme, giyinme, tuvalet ihtiyacını giderme gibi günlük aktiviteleri gerçekleştirme ve bağımsız hareket edebilme güçleşir. ${ }^{[2,4]}$ Serebral palsi prevalansı yüksek gelirli ülkelerde 1000 canlı doğumda 2,11 iken düşük gelirli ülkelerde 1000 canlı doğumda 2,9-3,7'dir. ${ }^{[1,5]}$

Serebral palsi, baskın olan motor bozukluk temelinde 3 tipe ayrilır; spastik, diskinetik ve ataksik. Spastik tip, \%80'lik bir oranla en sık görülen tiptir ve ikinci sıklıkta diskinetik tip görülür. Serebral palsi hastalarının büyük kısmında kliniğe hâkim olan spastisite, gerilme refleksinin aşırı uyarılması sonucu ortaya çıkan bir üst motor nöron bulgusudur ve inhibitör suprasegmental uyarıların kronik kaybı sonucunda, alfa motor nöron hiperaktivitesi oluşmasıyla ortaya çıkar. ${ }^{[1,2]}$

- İletişim adresi: Op. Dr. Elif Bolat, Ege Üniversitesi Tıp Fakültesi Hastanesi Beyin ve Sinir Cerrahisi Kliniği, Bornova, İzmir

Tel: 0530 -8781802 e-posta: welifsahin@gmail.com

- Geliș tarihi: 6 Mart $2021 \quad$ Kabul tarihi: 29 Mart 2021 


\section{TEDAVi}

Serebral palside, spastisite veya distoninin tedavisinde standart bir fikir birliği yoktur. Spastisite derecesi ve neden olduğu klinik etkiler ayrıntılı olarak değerlendirildikten sonra uygun bir tedavi planı oluşturulmalıdır. Spastisite tedavisinde; oral antispastik ajanlar gibi farmakolojik tedaviler, fizik tedavi, lokal botulinum toksin enjeksiyonları ilk basamak tedaviler olarak kabul edilmekle birlikte etkinlikleri her zaman istenilen düzeyde değildir. Bu nedenle zaman zaman ortopedik ve nöroşirürjikal prosedürlere ihtiyaç duyulabilmektedir. Uygulanan cerrahi prosedürler arasında miyelotomi, kordotomi, periferik nörotomi, selektif dorsal rizotomi, derin beyin stimülasyonu (DBS) ve intratekal baklofen (ITB) pompası yerleştirilmesi sayılabilir. [3]

Serebral palside spastisite ve distonide sıklıkla kullanılan terapötik (tedavi edici) ajanların başında baklofen ( $\mathrm{\gamma}$-aminobütirik asit) gelir. Baklofen, GABA-B reseptör agonisti olarak görev yaparak polisinaptik ve monosinaptik refleks yolaklarını inhibe eder.$^{[6-8]}$ Kanıt düzeyi yüksek çalışmalarda, intratekal baklofenin (iTB), "Kaba Motor İşlev Sınıflama Sistemi” (Gross Motor Function Classification System, GMFCS) dereceleri 4 ve 5 olan serebral palsili hastalarda, spastisitenin en etkin tedavi yöntemi olduğu gösterilmiştir. ${ }^{[1]}$

\section{Cerrahi Tedavi}

Oral baklofen tedavisine dirençli olan ya da oral baklofen tedavisinden yeterli yanıt alınamayan olgularda ITB yerleştirilmesi etkin bir seçenek olabilmektedir. Intratekal baklofen, spastisite tedavisinde ilk olarak 1984'te Penn ve Kroin tarafindan önerilmiştir. ${ }^{[9]}$ Dralle ve ark. 1985 'te iTB'nin serebral palsiye sekonder spastisite tedavisinde etkin olduğunu göstermişlerdir. ${ }^{[10]}$ iTB'nin popülarite kazanmasının nedenleri arasında oral alımda görülen yan etkilerin daha az görülmesi ve kan-beyin bariyerini oldukça kısıtlı oranda geçmesi sayılabilir. Intratekal olarak uygulanan sıvı baklofen, GABA reseptörlerini agonize ederek direkt ve selektif olarak spinal kord üzerine etki eder. Oral baklofen tedavi uygulamasında elde edilen 12-96 $\mathrm{\mu g} / \mathrm{ml}$ 'lik seviyelerle karşılaştırıldığında, ITB pompası yoluyla uygulandığında serebrospinal sıvıda $400 \mu \mathrm{g} / \mathrm{ml}$ gibi yüksek seviyelere ulaşır. Dolayısıyla terapötik etkinlik oldukça artırılmış olur. ${ }^{[6]}$

Sürekli iTB infüzyonu uygulamasında amaç spastisiteyi tamamen ortadan kaldırmak olmasa bile hayat kalitesini belirli bir seviyeye getirecek kadar spastisiteyi azaltmaktır. Bu nedenle ITB pompası tedavi hedefleri; hareket açıkığını artırmak, hareketi hızlandırmak, ve kontraktür gelişim riskini azaltmaktır. ${ }^{[6,7]}$
İntratekal baklofen pompası yerleştirmede önemli nokta ise hasta seçimidir. Klasik literatür bilgisi olarak konservatif metotlarla en az altı ay tedavi edilmiş ve spastisite açısından etkin bir sonuç elde edilememiş olgularda ITB pompası yerleştirilmesi önerilmektedir. Amaç, henüz kontraktür gelişmediyse, kontraktür gelişiminden önce etkin tedavi elde etmektir. Intratekal baklofenin erken uygulanması kontraktür gibi osteotendinöz (kemik-tendon) komplikasyonların gelişimini önlemektedir. Bu nedenle kabul gören güncel yaklaşım, medikal tedaviye yanıt alınamıyorsa, mümkünse kontraktür gelişiminden önce ITB pompasının yerleştirilmesi yönündedir. ${ }^{[6]}$

\section{Pompa Yerleştirilmesi}

İntratekal baklofen pompası yerleştirilme işleminin beş aşaması vardır; iTB pompa yerleştirilmesi için endikasyonların ve amaçların belirlenmesi, geçerli bir sonuç ölçütünü kararlaştırma, pre-implantasyon testi ile ITB pompasının etkinliğinin ön değerlendirilmesi, gerçek iTB pompa implantasyonu ve ameliyat sonrası izlemedir. ${ }^{[11]}$ iTB pompa yerleştirilmesi için endikasyonların ve amaçların belirlenmesi için multidisipliner bir değerlendirme gerekmektedir. Pompa yerleştirilmesine karar verildiğinde, tedavinin potansiyel etkinliği pre-implantasyon testiyle değerlendirilmelidir. Bu test ile, saf spastik veya mikst distonik ve spastik olgularda, tedaviden umulan sonuçlarla ilgili ön tahminde bulunulabilir. ${ }^{[1,12]}$ Pre-implantasyon testi, aynı zamanda, olgunun ailesinin tedavi kararı aşamasında karara dahil edilmesine olanak sağlar. Rutin pratiğe ve literatür bilgisine göre, pre-implantasyon testi, lomber ponksiyonla tek uygun doz, bolus şekilde baklofenin uygulanması esasına dayanır. Gerekli görülen olgularda doz progresif olarak artırılıp test tekrarlanabilir. Ayrıca tek doz intratekal baklofen uygulamasıyla pompa yerleştirilmesi kararı verilemeyen olgularda eksternal bir lomber drenaj kateteri yoluyla, doz titrasyonu ile sürekli infüzyon şeklinde uygulanabilir. ${ }^{[1,12,13]}$

Pre-implantasyon test dozuna veya infüzyon testine pozitif yanıt alındığında sürekli infüzyon pompası yerleştirilmesi işlemi düşünülebilir. ITP'deki pompa genel anestezi altında yerleştirilir. Yaklaşık $2 \mathrm{~cm}$ 'lik bir cilt insizyonu sonrası cilt altı dokular disseke edildikten sonra spinal kateter, lomber subaraknoid boşluğa perkütan olarak gönderilir. Alt ekstremite spastisitesinin kliniğe hâkim olduğu olgularda spinal kateter ucunun T10-11 (torakal vertebra 10-11)'de sonlanması hedeflenmelidir ve mutlaka skopi kontrolüyle hedeflenen seviyede olunup olunmadığı doğrulanmalıdır. Spinal kateterin sakral alana malpozisyonu sıklıkla görülebileceğinden işlem mutlaka skopi 
kontrolünde yapılmalıdır. Üst ekstremite spastisitesinin de belirgin olduğu olgularda kateter ucunun C7T1 (servikal vertebra 7 - torakal vertebra 1 ) seviyesine kadar çıkması gerekmektedir. ${ }^{[6]}$ Pompa genellikle abdomen sağ alt kadran bölgesine subkutan veya subfasiyal cep açılarak yerleştirilir. Subkutan olarak abdominal alana getirilen spinal kateter pompa ile bağlantılanarak açılan cebe yerleştirilir.

\section{Komplikasyonlar}

İntratekal baklofen pompası yerleştirilmesi, etkin bir tedavi seçeneği olmakla birlikte cerrahi tekniğe ve uzun dönem mekanik bir aletle tedavi gerekliliğine bağlı bir takım komplikasyonlar görülebilmektedir. Literatürde ITB pompa yerleştirilmesine bağlı genel komplikasyon oranı \%4-30 arasında bildirilmektedir. ${ }^{[14,15]}$ Elbette bu oranlar, komplikasyonun ne olduğuna, hastanın özelliklerine, yaşa ve takip süresine göre değişkenlik gösterir.

ITB tedavisinin majör komplikasyonları; ilaç ilişkili komplikasyonlar, erken ameliyat sonrası komplikasyonlar ve geç komplikasyonlar olarak sınıflandırılabilir. İlaç ilişkili komplikasyonlar ilaç yan etkileri, yüksek doza bağlı yan etkiler ve ilaç çekilme etkileridir. Erken ameliyat sonrası komplikasyonlar arasında serebrospinal sıvı kaçağı ve cilt altında birikmesi, postüral spinal baş ağrısı, yara yeri problemleri, pompa veya kateter bölgesinde enfeksiyon sayılabilir. Geç komplikasyonlar arasında pompa ve kateter problemleri gibi mekanik problemler, özellikle kaşektik hastalarda pompanın cildi kronik olarak rahatsız etmesi sonucu görülebilen ciltte yara açılması sayılabilir. Kateter ayrılması, kateterin kıvrılması, oklüzyonu, kayması, pompanın ters çevrilmesi, pompanın çalışmaması ise diğer görülebilen komplikasyonlardır. Pompa ve kateterle ilgili komplikasyonlar plan dâhilinde olmayan ikinci bir cerrahi gereksinimi doğurur. Bununla birlikte, ortalama ameliyat sonrası 5-6 yıllık zaman diliminde batarya ömrünün tükenmesi nedeniyle ikinci cerrahi kaçınılmazdır. ${ }^{[14-16]}$

Enfeksiyon, halen, teknolojik gelişmelerden etkilenmeyen major bir komplikasyon olarak karşımıza çıkmaktadır. Literatürde bildirilen enfeksiyon oranları \%9-15 arasında değişkenlik göstermektedir. Ameliyat sonrası dönemde 90 güne kadar görülen enfeksiyonlar akut, 90 günden sonra görülenler ise geç enfeksiyonlar olarak adlandırılır. Çeşitli mekanik komplikasyonlar nedeniyle gerçekleştirilen tekrarlayan cerrahiler enfeksiyon riskini artırmaktadır. Serebrospinal sıvı kaçağı da enfeksiyon riskini artıran faktörler arasındadır. En sık izole edilen mikroorganizma metisiline duyarlı Staphylococcus aureus (MSSA)'tur. Enfeksiyon geliştiğinde tedavi stratejileri arasında yara yeri drenajı ve irrigasyonla pompanın korunması, antibiyotik uygulanması, pompanın çıkarılması, uygun antibiyoterapi sonrasında aynı tarafa ya da karşı tarafa yeni bir pompanın yerleştirilmesi yer alır. Birçok çalışmada pompanın subfasiyal yerleştirilmesinin, subkutan yerleştirmeyle karşılaştırıldığında enfeksiyon riskini azalttığı gösterilmiştir. ${ }^{[6,15]}$

\section{SONUÇ}

İntratekal baklofen tedavisi, uygun seçilmiş olgularda hem serebral hem de spinal kaynaklı spastisiteyi azaltarak hayat kalitesini ve fonksiyonel bağımsız hareket yeteneğini artırır. Medikal tedaviyle istenilen yanıt alınamayan olgularda, özellikle kontraktür gelişiminden önce, intratekal baklofen tedavisi değerlendirilmelidir.

\section{KAYNAKLAR}

1. Bonouvrie L, Becher J, Vles J, Vermeulen RJ, Buizer AI; IDYS Study Group. The Effect of Intrathecal Baclofen in Dyskinetic Cerebral Palsy: The IDYS Trial. Ann Neurol 2019;86:79-90. Crossref

2. Rosenbaum $P$, Paneth $N$, Leviton $A$, Goldstein $M, B a x ~ M$, Damiano D, Dan B, Jacobsson B. A report: the definition and classification of cerebral palsy. Dev Med Child Neurol Suppl 2007;109:8-14. https://pubmed.ncbi.nlm.nih. gov/17370477/

3. Kim JH, Jung NY, Chang WS, Jung HH, Cho SR, Chang JW. Intrathecal baclofen pump versus globus pallidus interna deep brain stimulation in adult patients with severe cerebral palsy. World Neurosurg 2019;126:550-6. Crossref

4. Miller F. Cerebral Palsy. New York, NY: Springer-Verlag; 2005. Crossref

5. Oskoui M, Coutinho F, Dykeman J, Jetté N, Pringsheim T. An update on the prevalance of cerebral palsy: a systematic review and meta-analysis. Dev Med Child Neurol 2013;55:509-19. Crossref

6. UçarT, KazanS, TurgutU, Samancı NK. Spastisitede intratekal baclofen tedavisi sonuçları [Outcomes of intrathecal baclofen (ITB) therapy in spacticity]. Turk Neurosurg 2011;21:59-65. http://www.turkishneurosurgery.org.tr/ pdf/pdf_JTN_818.pdf

7. Civelek GM, Atalay A. Serebral palside spastisite tedavisi. J Curr Pediatr 2016;14:136-41. Crossref

8. Young RR, Delwaide PJ. Drug Therapy: spasticity (second of two parts). N Engl J Med 1981;304:96-9. Crossref

9. Penn RD, Kroin JS. Intrathecal baclofen alleviates spinal cord spasticity. Lancet 1984;8385:1078. Crossref

10. Dralle D, Müller H, Zierski J, Klug N. Intrathecal baclofen for spasticity. Lancet 1985;326:1003. Crossref

11. Dan B, Motta F, Vles JSH, Vloeberghs M, Becher JG, Eunson P, Gautheron V, Lütjen S, Mall V, Pascual-Pascual SI, Pauwels $P$, Røste GK. Consensus on the appropriate use of intrathecal baclofen therapy in paediatric spasticity. Eur J Paediatr Neurol 2010;14:19-28. Crossref

12. Armstrong RW, Steenbok P, Cochrane DD, Kube SD, Fife SE, Farrell K. Intrathecally administered baclofen for treatment of children with spasticity of cerebral origin. J Neurosurg 1997;87:409-14. Crossref 
13. Samson-Fang L, Gooch J, Norlin C. Intrathecal baclofen withdrawal simulating neuroleptic malignant syndrome in a child with cerebral palsy. Dev Med Child Neurol 2000;42:5615. Crossref

14. Imerci A, Rogers KJ, Pargas C, Sees JP, Miller F. Identification of complications in pediatric cerebral palsy treated with intrathecal baclofen pump: a descriptive analysis of 15 years at one institution. J Child Orthop 2019;13:529-35. Crossref
15. Bayhan IA, Sees JP, Nishnianidze T, Rogers KJ, Miller F. Infection as a complication of intratechal baclofen treatment in children with cerebral palsy. J Pediatr Orthop 2016;36:3059. Crossref

16. Haranhalli N, Anand D, Wisoff JH, Harter DH, Weiner HL, Blate M, Roth J. Intrathecal baclofen therapy: complication avoidance and management. Childs Nerv Syst 2011;27:42127. Crossref 